\title{
有机催化芳香化反应的研究进展
}

\author{
贾乾发李娅琼林银河* \\ (长江师范学院化学化工学院 重庆市无机特种功能材料重点实验室 重庆涪陵 408100)
}

\begin{abstract}
摘要 芳香族化合物是一类具有特殊香味的化合物, 其结构广泛存在于天然产物和药物分子中. 在众多小分子药物结 构中以苯环结构最为常见. 因此，探究构建芳香结构化合物的方法也受到极大的关注并取得了重要的突破，其中以金 属催化非环状炔烃或烯烃的环合为主. 近年来, 有机催化在构筑苯环及其衍生物的过程中得到充分应用. 与金属催化 相比，有机催化合成含苯环结构化合物的反应可以避免在苯环上引入定位基团或导向基团的步骤，且具有良好的底物 适用性. 同时, 有机催化反应具有高效、操作简便、反应条件温和及原子经济性等优点，引起了合成化学工作者的广泛 关注. 综述了多类有机小分子催化的非环状前体化合物环化合成多取代苯环结构的反应特点和研究进展.
\end{abstract}

关键词 有机催化; 芳香化; 成环反应; 研究进展

\section{Recent Advances in Organocatalyzed Aromatization Reactions}

\author{
Jia, Qianfa Li, Yaqiong Lin, Yinhe* \\ (Chongqing Key Laboratory of Inorganic Special Functional Materials, College of Chemistry and \\ Chemical Engineering, Yangtze Normal University, Fuling, Chongqing 408100)
}

\begin{abstract}
Aromatic compounds possess a particular fragrance and are widely present in natural products and pharmaceuticals. Among them, benzenes are the most abundant substructures of commercially available small-molecule drugs. Therefore, a variety of synthetic methodologies for the construction of aromatic compounds have been pursued vigorously and some significant progresses have been achieved. The dominant methods are transition metal-catalyzed benzannulation of enynes with alkynes to construct the functionalized benzenes. The synthesis of substituted benzene derivatives receives constant attentions since the formation and development of organocatalysis. Compared to metal catalysis, the organocatalytic benzannulation reaction avoids the introduction of a direct group into the pre-existed arene ring and appears to be tolerant of a broad range of substrates. While organocatalysis has emerged as a promising green and effieient synthetic tool and attracted a great deal of attention from synthetic chemists. The development of organocatalyzed aromatization reactions from acyclic starting materials is featured.
\end{abstract}

Keywords organocatalysis; aromatization; annulation; research progress

多取代苯等芳香环是有机分子中最基本的母核结 构之一，在 200 种最畅销的药物里接近 $80 \%$ 的分子结构 中都至少含有 1 个苯环结构 ${ }^{[1]}$. 例如环丙沙星化合物 1 作为第三代喹诺酮类抗菌药物, 对革兰阴性菌作用效果 明显，同时具有广谱的抗菌活性，是广泛应用于临床治 疗的抗菌药物 ${ }^{[2]}$; 非甾体抗炎药物卡洛芬 2 中则以咔唑 结构为主要骨架 ${ }^{[3]}$; 轴手性联芳基化合物 3 作为手性配 体或催化剂被广泛应用于催化反应中, 并表现出非常好 的性能 ${ }^{[4]}$ (图 1). 传统合成多取代苯类化合物的方法主要 有: (1)在已有苯环结构上引入新的官能团, 典型方法包
括芳环的亲电或亲核取代反应 ${ }^{[5]}$ 或过渡金属催化的偶联 反应(Scheme 1) ${ }^{[6]}$;(2)由过渡金属催化的非环状炔烃或 烯烃的组合构建苯环结构 (Scheme 1) ${ }^{[7]}$. 然而这些合成 方法往往需要多步反应且收率较低, 或需要导向基团的 存在才能实现较好的区域选择性, 效率较低. 另一方面, 反应的经济性和环境友好性也是需要考虑的因素. 有机 催化的概念由 MacMillan 在 21 世纪初提出并得到充分 的发展, 成为继金属催化和酶催化化学反应的主要类型 之一. 有机催化反应具有条件温和、操作简单等优点, 为高效构建多取代苯环结构化合物提供了一条新的合

\footnotetext{
* Corresponding author. E-mail: 20170168@yznu.cn

Received January 6, 2020; revised February 16, 2020; published online February 29, 2020.

Project supported by the Yangtze Normal University (Nos. 2017KYQD123, 2018QNRC17).

长江师范学院科研启动(Nos. 2017KYQD123, 2018QNRC17)资助项目.
} 


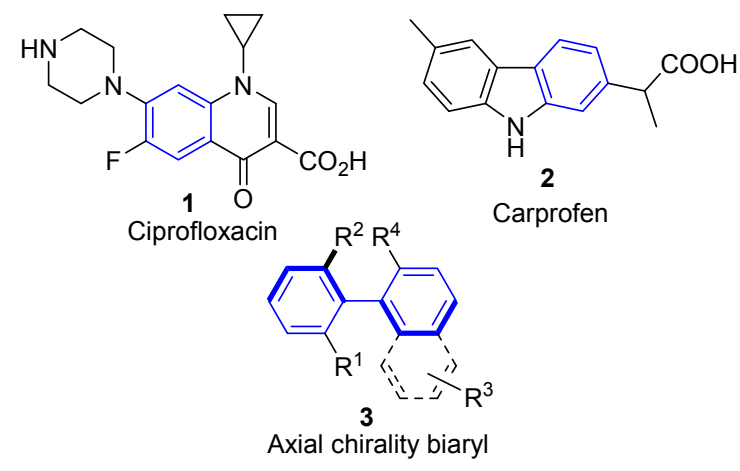

图 1 典型含苯环结构的分子

Figure 1 Selected compounds containing benzene rings

成路径并得到广泛关注. 通过对底物的预先官能化, 经 有机催化可以实现构建苯环骨架的同时导入不同官能 才，完成芳香环的多样性合成(Scheme 1). 本文基于不 同种类小分子催化剂催化合成多取代苯环结构的方法, 简述不同种类催化剂的催化特点及其应用. 由化学计量 的催化剂参与的反应本文不讨论.

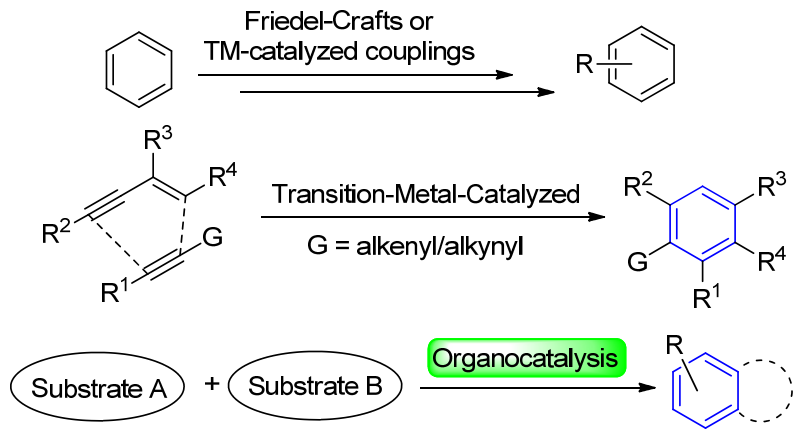

图式 1 多取代苯环的合成路径

Scheme 1 Synthetic strategies for multi-substituted benzene

\section{1 有机胺催化芳香化反应}

2005 年, Ramachary 课题组 ${ }^{[8]}$ 报道了首例有机催化 Hagemann 酯和醛的串级 Claisen-Schmidt 异构/芳构化反 应，得到一系列多取代的苯酚结构化合物. 该反应在小 分子催化剂 A1 催化作用下与 Hagemann 酯 4 经原位生 成的二烯胺中间体 9 得到 2-芳叉 Hagemann 酯 10, 而醛 与催化剂作用生成的亚胺正离子 11 能很好地与二烯胺 中间体 10 发生 Mannich 反应, 进一步经逆-Mannich 反 应、异构/芳构化生成目标产物 6. 紧接着, 该小组 ${ }^{[9]}$ 利用 同样的策略, 实现了吡咯烷 A2 催化的 Hagemann 酯 4 与亚硝基苯 7 的串级反应, 以较高产率得到二芳基胺类 化合物 8 (Scheme 2). 2007 年, Hong 小组 ${ }^{[10]}$ 报道了吡咯 烷或脯氨酸催化的 $\alpha, \beta$-不饱和醛的分子间环加成反应, 通过 $[3+3]$ 、 [4+2]形式实现了多取代芳香醛的合成. 反 应采用不同的催化剂组合, 在一些反应中需要加入过量
的氧化剂如二氧化锰 $\left(\mathrm{MnO}_{2}\right)$ 或 2,3-二氯-5,6-二氧基-1,4苯醌(DDQ)来实现产物的芳构化. 同时，该反应还能实 现不饱和醛的分子内环加成反应, 为具有生物活性小分 子的构建提供了一条简单、高效的合成方法.
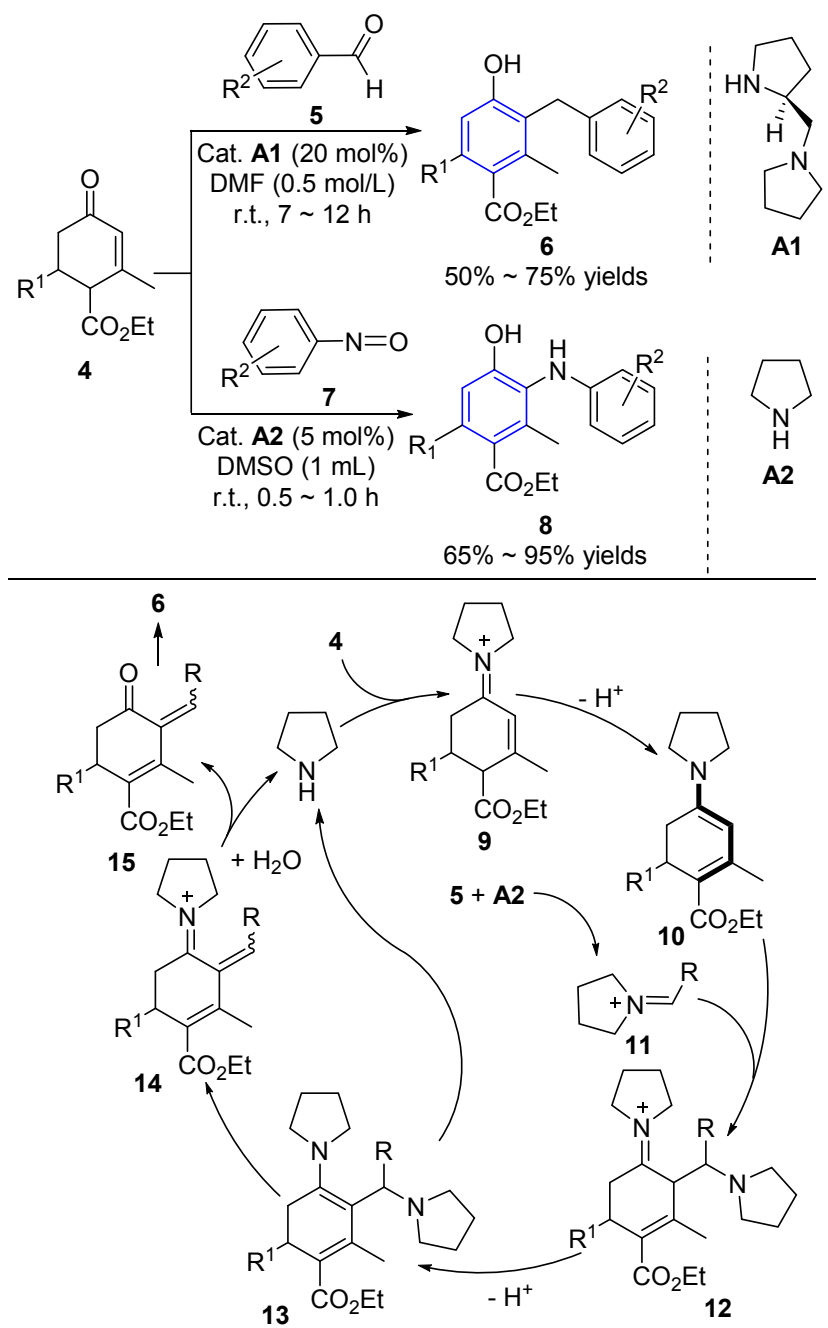

图式 2 基于推挽式二烯胺中间体合成多取代苯环化合物 Scheme 2 Synthesis of highly substituted benzenes based on push-pull dienamine intermediate

2010 年, 许鹏飞课题组 ${ }^{[11]}$ 发展了一例吡咯烷 A2 催 化 2-(2-氧乙基)-苯甲醛 16 与硝基烯烃 17 的串级环化反 应，历经 Michael/Henry 反应、脱水和芳构化得到多取代 菱环化合物 18 . 反应对芳香或杂环取代的硝基烯烃底 物有很好的适应性，以中等收率得到目标产物，而烷基 取代的硝基烯烃则不能发生反应(Eq. 1).

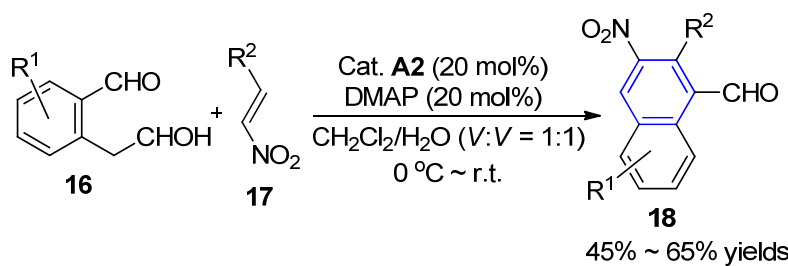


2012 年, 史达清小组 ${ }^{[12]}$ 报道了靛红 20 与 3-氨基取 代环已烯酮 19 的反应, 当底物 3-氨基取代环已烯酮环 上取代基为氢原子时, 该反应在催化量的 $L$-脯氨酸(A3) 作用下实现呋啶类衍生物 21 的高效合成. 反应在 1 3 $\mathrm{h}$ 即可完成, 能以 $60 \% \sim 82 \%$ 的收率得到芳构化产物 (Eq. 2).

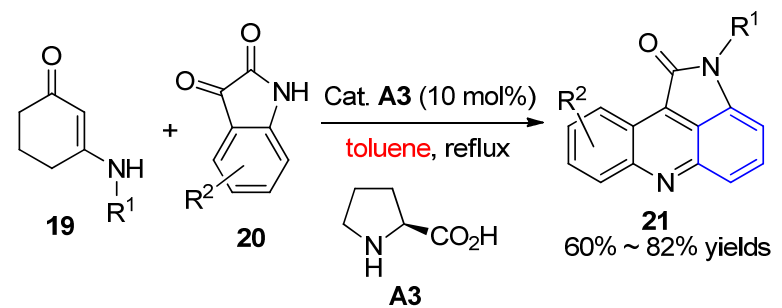

王卫课题组 ${ }^{[13]}$ 报道了有机催化 Michael/Aldol 芳构 化反应, 实现了 $\beta$-烷基取代烯醛 22 的二聚以及与烯醛 23 的环合反应(Eq. 3), 以高产率及非常好的区域/化学 选择性地得到多取代芳香醛类化合物 24.

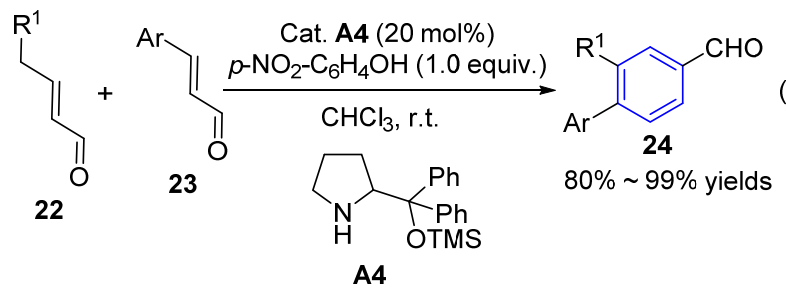

具有轴手性的芳香化合物广泛存在于天然产物、药 物分子、手性催化剂和功能分子中, 其化学合成备受关 注. 这类分子的合成方法主要是对反应底物中已存在的 芳香基团进行不对称的取代或修饰，从而构建出手性 轴. 但在多取代芳环结构中, 逐步取代的方法往往会受 到区域选择性的限制而需要较长的合成步骤. 而且当手 性轴两边空间位阻相差不大的时候, 通过不对称取代的 方法就很难能得到高的立体选择性. 因此, 通过直接构 建芳香环结构来制备轴手性化合物的方法则具有独特 的优势.

2014 年, Sparr 小组 ${ }^{[14]}$ 首次报道了在有机催化 Aldol 反应合成芳香环的同时，实现轴手性的构建. 反应以 5 $\mathrm{mol} \%$ 的吡咯烷基-四氮唑(A5)为催化剂, 室温下完成底 物 25 的高效转化, 经由烯胺活化底物、中心手性向轴手 性的转移及芳构化过程, 以中等到良好的收率和高达 98\%的非对映体过量值 $(e e)$ 得到联䒺甲醛类化合物 26 (Scheme 3). 随后, 该小组 ${ }^{[15]}$ 利用同样的策略, 在相同 催化剂 $\mathbf{A 5}$ 作用下, 将底物结构更换为 $\mathbf{2 7}$ 时, 能以高对 映选择性得到轴手性联芳基酰胺类化合物. 反应在 30 $\min \sim 2 \mathrm{~h}$ 即可完成, 再经嗍氢化钠还原得到更稳定的羟 甲基取代的芳基酰胺产物 28 (Scheme 3).

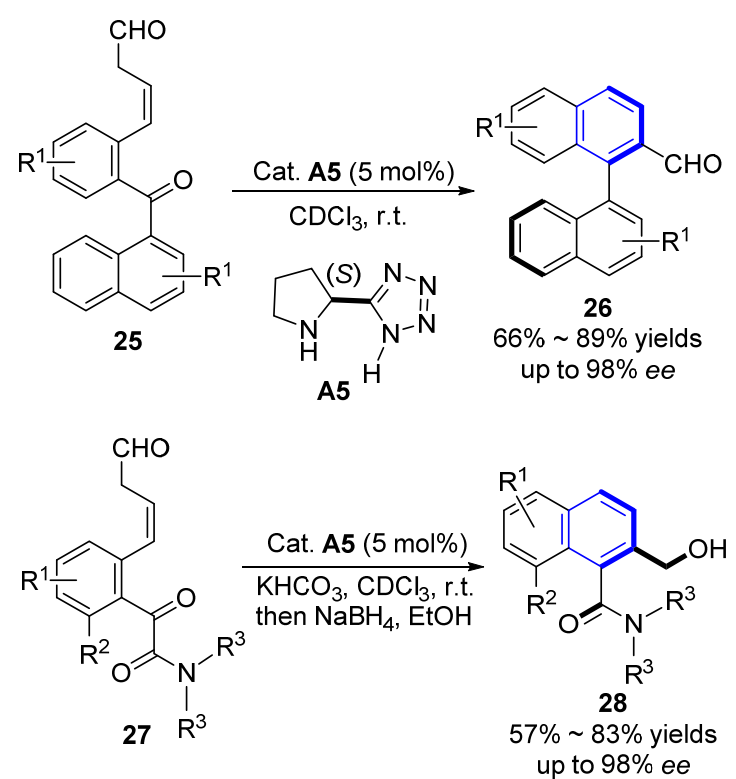

图式 3 有机催化芳环化合成轴手性联芳基化合物及芳香酰 胺化合物

Scheme 3 Organocatalytic synthesis of axially chiral biaryls and aromatic amides by arene formation

2015 年, Lee 小组 ${ }^{[16]}$ 报道了由 $L$-脯氨酸(A3)催化的 1,4 -荎醌或 1,4 -葱醌 29 与 $\alpha, \beta$-不饱和醛 30 的 [4+2]环加 成反应，合成了一系列葸醌类或四苯并二酮类化合物 31. 机理研究显示脯氨酸与 $\alpha, \beta$-不饱和醛作用形成二烯 胺中间体, 当底物结构不同或催化剂结构中羧基与底物 之间存在氢键作用时，可能得到两种区域选择性产物. 该反应为葱醌或四苯并二酮类化合物的合成提供一条 简单高效的合成方法(Eq. 4).
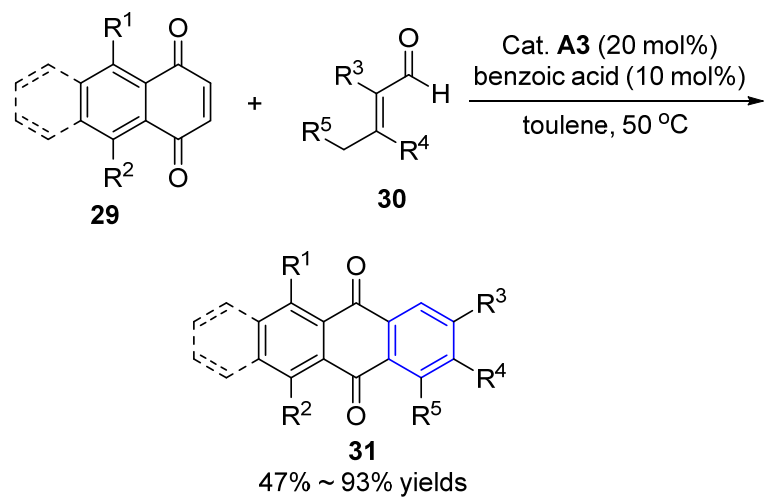

2015 年, Vitale 和 Michelet 课题组 ${ }^{[17]}$ 报道了三氟甲 磺酰亚胺(A6)催化炔-醛偶联苯环化合成多取代荎的方 法. 传统方法由炔烃参与菜环中苯环构建的 $[4+2]$ 环化 过程主要是金属或路易斯酸催化完成的，而该小组首次 采用三氟甲磺酰亚胺作为催化剂实现多取代萗的构建. 苯环上和 $\alpha$ 位有不同取代基的苯乙醛底物 32 均能很好 地与各种取代炔烃底物 33 发生反应，同时该反应还能 
在炔烃与环氧化物或二甲基乙缩醛类底物中顺利发生, 同样得到多取代萗环产物(Eq. 5).<smiles>[R]C(C=O)c1[R]cccc1</smiles>

32
33<smiles>[R]C#Cc1[R]ccc1</smiles>

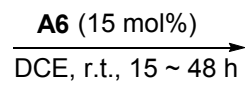<smiles>O=S(=O)(NS(=O)(=O)C(F)(F)F)C(F)(F)F</smiles>

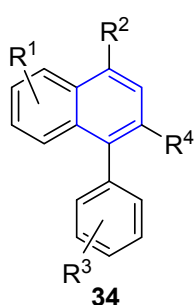

$41 \% \sim 78 \%$ yields
2018 年, 蒋琳和袁明龙等 ${ }^{[18]}$ 报道了含烯丙基砜取 代的 1,3-双亲核试剂 35 与不饱和醛 36 的[3+3]苯环化 反应. 以 $20 \mathrm{~mol} \%$ 的吡咯烷(A2)作催化剂, 与不饱和醛 作用生成亚胺正离子中间体 38, 经 Michael 加成得到烯 胺中间体 39, 再经异构化、1,3-氢迁移、分子内的亲核 加成环合反应得到产物 42 并脱除催化剂实现循环过程, 最后经空气氧化得到目标产物 37 . 该反应很好地避免 了过渡金属以及化学计量的强碱的使用, 在绿色、温和 条件下实现多取代苯化合物的多样性合成(Scheme 4).
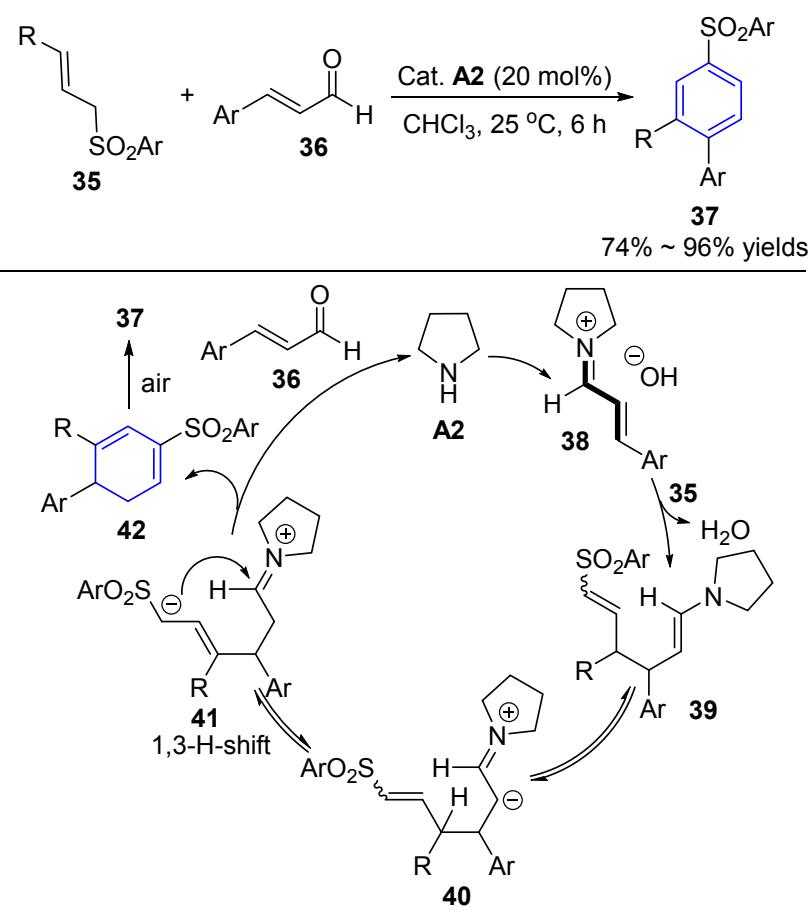

图式 4 二级胺催化 $[3+3]$ 苯环化合成多取代苯化合物 Scheme 4 Secondary amine-catalyzed [3+3] benzannulation to access polysubstituted benzenes

2019 年, 许鹏飞课题组 ${ }^{[19]}$ 成功利用环己二胺衍生 的硫脲类手性氢键催化剂, 通过芳香化反应在吲哚的碳 环上构筑了轴手性, 得到的含有吲哚骨架的轴手性联芳 基二酚可以作为一类具有较高催化活性的不对称催化 剂. 通过对底物结构和催化剂的笁选，作者选定 5-着基
吲哚 43 和氮杂对苯醌类底物 44 作为起始原料, 经条件 优化及底物扩展可以定量的产率、高达 $99 \%$ 的 ee 值得 到最终轴手性产物 45 (Eq. 6). 进一步考察了反应机理, 通过核磁实验发现催化剂 A7 与底物 44 之间存在较强的 氢键作用，同时底物 5-差基吲哚 43 中的羟基与催化剂 的硫原子也存在弱相互作用，并通过羟基保护实验证明 底物中羟基的存在对反应起到了至关重要的作用. 另 外，作者将得到的轴手性联芳基二酚产物作为催化剂用 于催化酮的不对称烯丙基化反应. 结果表明，不论是催 化活性还是立体选择性的控制能力都优于传统轴手性 联二菜酚(BINOL), 反应效果甚至比已有报道的最优催 化剂还要好. 该实验充分说明新合成的这类轴手性骨架 在不对称催化领域有着巨大的开发潜力. 最后，作者对 手性氢键催化苯环化反应进行了放大反应和催化剂回 收利用实验, 均取得令人满意的结果. 这一方法的建立, 实现了由有机催化一有机催化剂的完美转化, 为轴手性 吲哚类化合物的合成提供了开拓性的思路，也拓展了氢 键催化的应用范围.

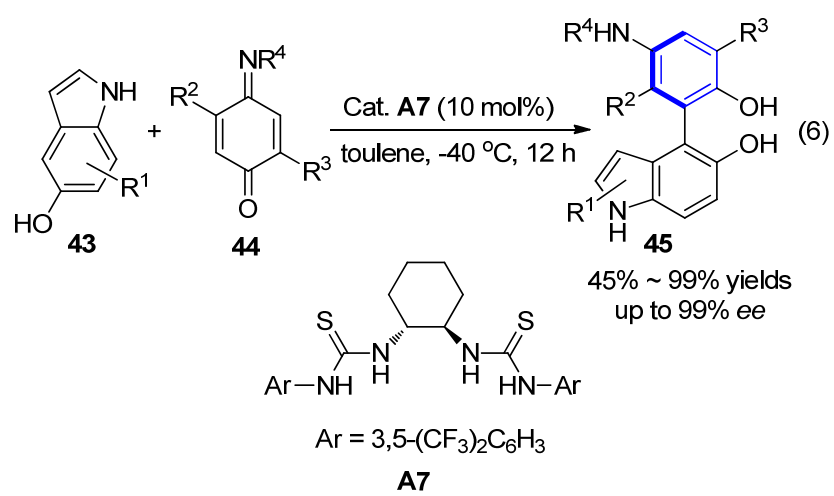

\section{2 有机碱催化芳香化反应}

有机碱是一类结构简单、便宜易得的化合物，如吡 啶、1,8-二氮杂二环十一碳-7-烯(DBU)和金鸡纳碱等都 是一些常见的有机碱. 利用有机碱作为小分子催化剂催 化反应，可以通过分子中所含的氮原子等富电子中心与 底物作用形成活化中间体来启动化学反应，并利用自身 的结构因素来控制反应的立体选择性，且催化剂容易从 产物中脱离完成催化循环.

2005 年, Nair 小组 ${ }^{[20]}$ 报道了吡啶介导的丁炔二酸二 酯 47 与环丁烯 1,2-二酮 46 的反应，通过调节吡啶的量 可以选择性地实现六取代苯环衍生物 48 或环戊烯二酮 类化合物 49 的简捷合成. 当反应以吡啶为溶剂时，可以 中等到良好的收率得到全取代的对苯二酚产物 $\mathbf{5 0}$; 当 使用催化量的吡啶时，反应主要生成环戊烯二酮产物， 仅有 $10 \% \sim 15 \%$ 的苯环化产物(Scheme 5). 紧接着，该 课题组报道了催化量的二甲氨基吡啶催化 $\beta$-酮酯与丁 


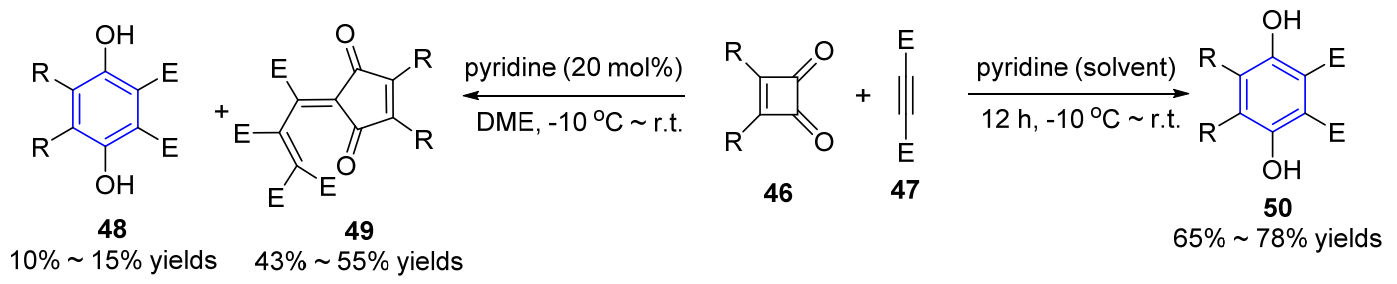

图式 5 吡啶催化丁炔二酸二甲酯(DMAD)与环丁烯 1,2-二酮的反应

Scheme 5 Pyridine catalyzed reaction of DMAD with cyclobutene-1,2-diones

炔二酸二甲酯的反应，同样得到多取代苯环产物和联芳 基化合物. 但该反应的底物适用范围比较受限, 底物 $\mathbf{4 7}$ 中酯基的存在对反应的顺利发生起到关键性作用.

基于同样的策略, 薛松小组 ${ }^{[21]}$ 进一步将 Nair 报道 的反应中的底物扩展到 $\beta$-二酮 $\mathbf{5 1}$ 与丙炔酸乙酯 $\mathbf{5 2}$ 或丁 炔二酸二甲酯 54, 分别在 $20 \mathrm{~mol} \%$ 的 4-二甲氨基吡啶 (DMAP)或 $25 \mathrm{~mol} \%$ 吡啶/叔丁醇钾催化条件下得到多取 代苯环产物(Scheme 6).

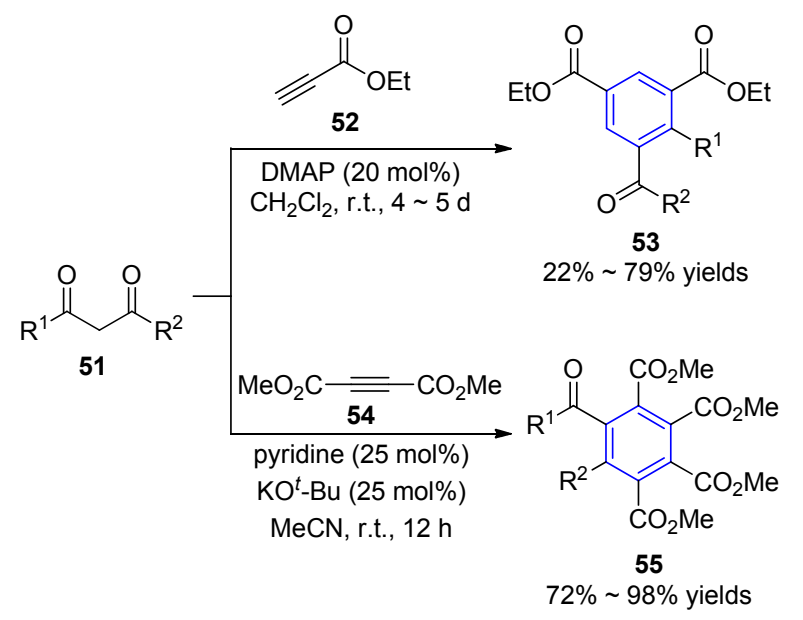

图式 6 DMAP 或吡啶/叔丁醇钾催化苯环化反应

Scheme 6 DMAP or pyridine/potassium tert-butoxide catalyzed benzannulation

Hamdi 和 Silva 小组 ${ }^{[22]}$ 报道了一锅法合成苯并香豆 素 58 的方法, 由催化量的 4-吡咯取代吡啶 B1 催化化合 物 56 与 57 的反应, 经 1,4-共轭加成、脱羧、芳构化得 到目的产物. 其中底物 57 中 3-羧基的存在对反应的发 生起到决定性作用(Eq. 7).<smiles>[R]c1cccc2cc(/C(O)=C/C(C)=O)c(=O)oc12</smiles>

2014 年, Babu 等 ${ }^{[23]}$ 报道了一例简单高效一锅法合 成杂芳基取代苯环产物的方法，反应以 $5 \mathrm{~mol} \%$ 的 1,4-二 氮杂二环 [2.2.2]辛烷 (B2, DABCO)为催化剂, 乙烯基丙 二腈 59 与杂芳基硝基烯烃 60 经 Michael 加成反应, 在 碱性条件下进一步环合和异构化, 最后经氧化得到杂芳 基取代的苯环结构化合物 61. 值得注意的是，该小组对 合成的产物进行了活性测试, 结果显示部分化合物在抗 结核和抗菌方面表现出很好的广谱活性(Eq. 8).

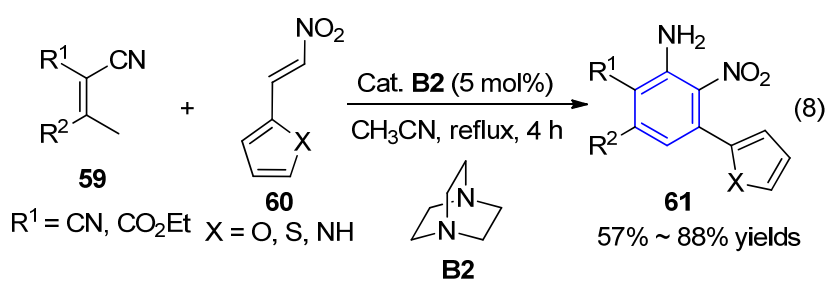

Salvio 和 Bella 课题组 ${ }^{[24]}$ 实现金鸡纳碱 B3 催化不对 称合成 $2^{\prime}, 2^{\prime}$-联菱酚类轴手性化合物 67 的高效合成. 通 过条件优化，该反应在 $15 \mathrm{~mol} \%$ 的金鸡纳碱催化下，以 四氢呋喃为溶剂, $4{ }^{\circ} \mathrm{C}$ 下反应足够长时间, 能以几乎定 量的产率得到联苶酚类轴手性产物. 同时, 该反应同样 能以高收率实现克级规模的制备, 反应产物通过重结晶 能得到高达 $98 \%$ 的 $e e$ 值(Eq. 9). 尽管反应的对映选择性 不太理想, 但仍能为探索新型有机催化构建轴手性的研 究奠定基础.

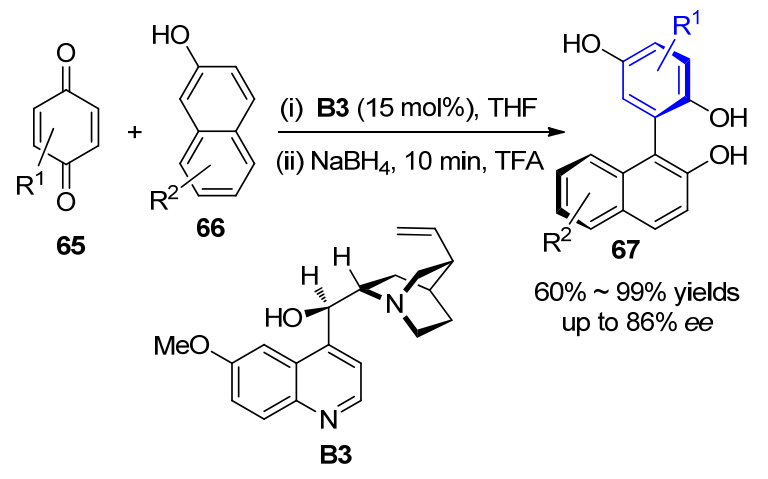

(9)

2017 年, 徐显秀小组 ${ }^{[25]}$ 报道了一锅法合成菲啶衍 生物 70 的简便方法, 在 $30 \mathrm{~mol} \%$ 的 DBU 催化作用下, 一系列 2-异氧基查耳酮 68 与活泼亚甲基酮 69 经 
Michael 加成、分子内异腈亲电环化、Aldol 缩合，再经 脱水、脱酰基并被氧气氧化和芳构化得到结构多样的菲 啶产物. 该反应通过多步多米诺转化可以一次性实现连 续双环及三个 $\mathrm{C}-\mathrm{C}$ 键的构建, 为合成三环骨架结构化 合物提供了有效的合成方法(Eq. 10).

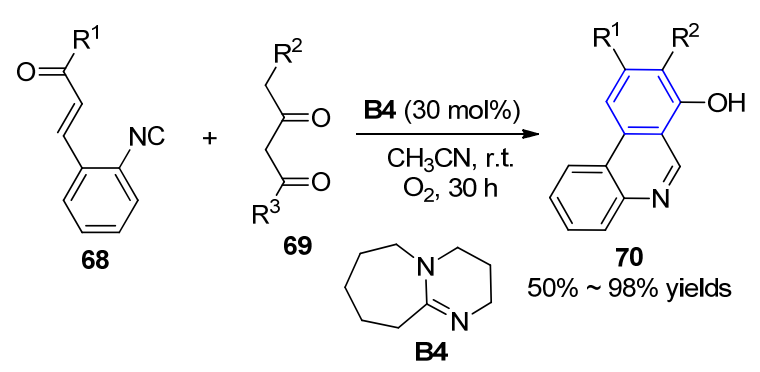

(10)

\section{3 氮杂卡宾催化苯环化反应}

氮杂卡宾 (NHC) 作为有机小分子催化剂中的一员, 具有很好的亲核性, 其对羰基化合物的催化反应表现出 独特的活化模式和高效的催化活性及立体选择性 ${ }^{[26]}$. 通过 NHC 催化活化不同的反应类型和底物可以高效地 合成出各种结构新颖的化合物, 这些化合物为篎选高活 性药物小分子提供了基础. 利用氮杂卡宾催化反应构建 环化产物及与氧化环境兼容性好的特点，一方面通过 $\mathrm{NHC}$ 催化剂实现环化反应的动力学调控, 确保芳环构 建时的区域选择性和化学选择性控制; 另一方面, 通过 引入串联氧化芳香化过程, 为催化环化反应提供额外的 热力学推动力, 完成热力学稳定的芳香体系的构建. 两 方面相辅相成, 为多取代芳环化产物的合成提供了一条 非常高效的捷径.

2014 年, 池永贵课题组 ${ }^{[27]}$ 首次实现利用氮杂卡宾 催化 $[3+3]$ 环加成构建苯环的反应. 以简单易得的烯醛 与烯酮为起始原料, 活化后的氮杂卡宾首先对烯醛 71 发生加成及质子化得到 Breslow 中间体 74, 再在苯醌氧 化剂(DQ)作用下得到 $\alpha, \beta$-不饱和酰基唑中间体 75, 在碱 性条件下质子化生成乙烯基烯醇式中间体 76, 该中间 体的 $\gamma$-碳对烯酮 72 发生 Michael 加成反应得到中间体 77, 接着发生分子内的 Aldol 缩合、内酯化生成产物 80 并脱除卡宾催化剂实现催化循环. 产物 80 再经脱羧、氧 化得到最终四取代苯环产物 73. 底物普适性考察显示, 其中烯醛和烯酮底物的 $E / Z$ 异构体对反应结果影响不 大, 均能很好的得到苯环化产物(Scheme 7). 同时, 反 应产物也能进一步发生转化, 通过一步反应即能得到一 些天然产物结构中的核心骨架如葋酮和异吲哚酮等结 构. 该方法高区域选择性地一步快速构建了多取代芳 环, 为相应复杂结构化合物的合成提供了全新的合成思 路.

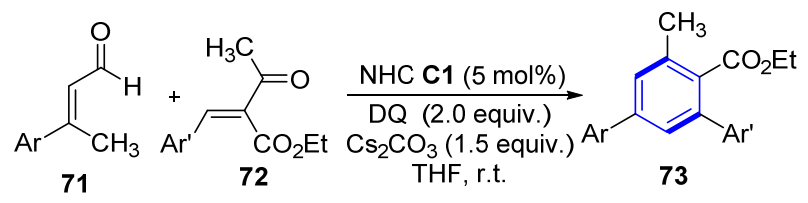

$$
\mathrm{Mes}_{\mathrm{C} 1}^{-\mathrm{N}_{-}}{ }_{-}^{\mathrm{Cl}^{-}}
$$

$41 \% \sim 88 \%$ yield

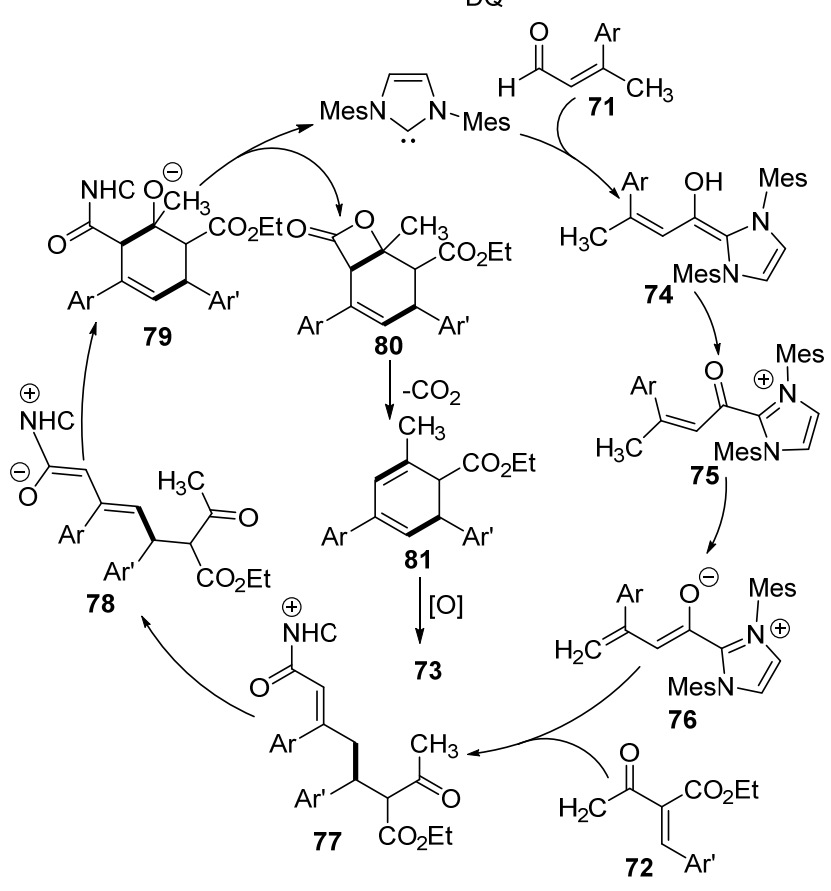

图式 7 有机催化 $[3+3]$ 环加成构建苯环的反应及机理 Scheme 7 Benzene construction via organocatalytic formal $[3+3]$ cycloaddition reaction and mechanism

不久, 该小组 ${ }^{[28]}$ 再次利用氮杂卡宾催化实现 $\alpha, \beta$ $\gamma, \delta$-不饱和醛 82 的 $\delta$ 位活化, 与 1,3 -二酮 83 反应得到多 取代芳烃化合物 84. 当底物 82 中 $\delta$ 位被苯酚酯单元取 代时，反应则按另一途径得到 3-亚基茚苯酞产物 85. 该 反应最大亮点在于在 $\alpha, \beta-\gamma, \delta$-不饱和醛的 $\beta$ 位引入取代 基, 从而限制 $\beta$ 碳的反应活性, 实现远程 $\delta$ 位的活化, 通 过底物结构控制产物的化学/区域选择性得到多取代芳 烃化合物(Scheme 8).

2017 年, 池永贵等 ${ }^{[29]}$ 报道了卡宾催化 $\beta$-甲基- $\alpha, \beta$ 不饱和醛 86 与呋喃酮 87 的 $[5+5]$ 反应, 成功合成香豆 素结构化合物 88, 并成功将该策略应用于具有重要生 物活性的天然产物的合成中 (Scheme 9). 最近, 该小 组 ${ }^{[30]}$ 进一步将反应底物扩展到 $\beta$-甲基- $\alpha, \beta$-不饱和酯类 化合物, 与氧杂二烯底物在卡宾催化下, 采用更廉价易 得的四甲基哌啶氮氧化物(TEMPO)作为氧化剂实现了 苯环化反应, 高产率地得到了 $2,4,6$-三取代的苯乙酮类 产物。 


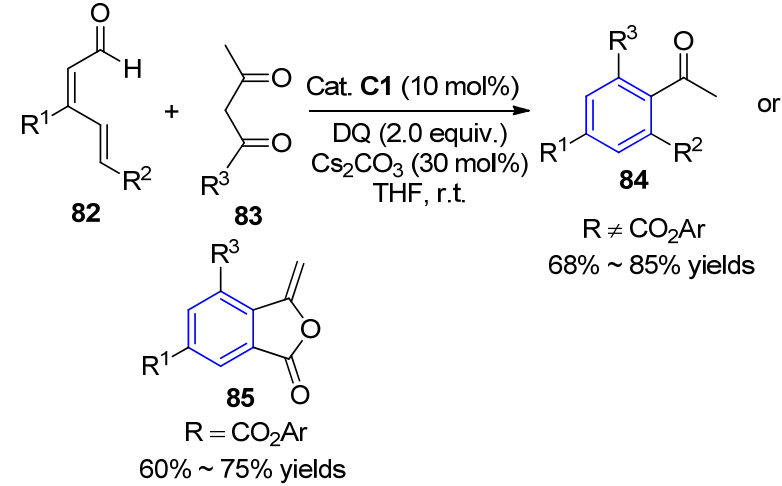

图式 8 氮杂卡宾催化不饱和醛的 $\delta$-碳 LUMO 活化.

Scheme $8 \quad N$-Heterocyclic carbene-catalyzed $\delta$-carbon LUMO activation of unsaturated aldehydes.

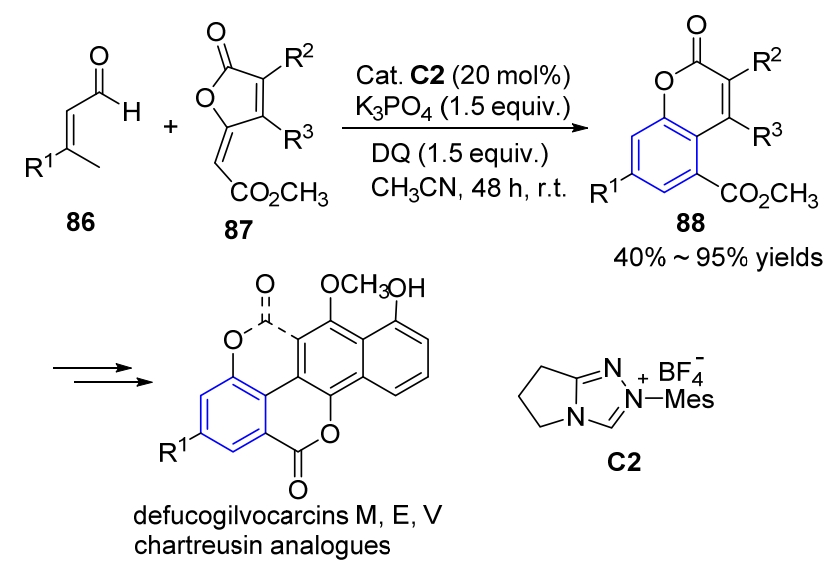

图式 9 卡宾催化 $[5+5]$ 反应合成香豆素结构

Scheme 9 Carbene-catalyzed formal $[5+5]$ reaction for coumarin construction

2019 年, 池永贵课题组 ${ }^{[31]}$ 和王兴旺小组 ${ }^{[32]}$ 相继报 道了卡宾催化环戊烯二酮 89 的去对称化, 直接构建苯 环结构得到了二氢化荫产物 90, 通过远程手性控制实 现全季碳手性中心的构建(Eq. 11). 基于该策略, 可以完 成部分螺环分子或天然产物的结构片段的高效合成, 同

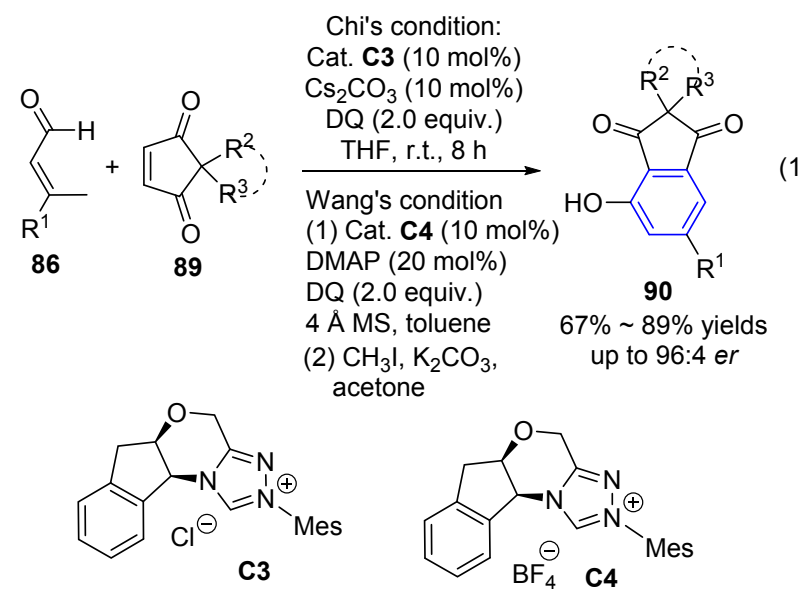

时还可以对产物进行多种结构转化. 两个小组的工作类 似，区别仅仅在于催化剂中负离子和碱的使用不同，而 王兴旺小组则可以实现产物的一锅法甲基化过程.

2015 年, Lupton 小组 ${ }^{[33]}$ 报道了氮杂卡宾催化酯 91 的氧化还原异构化反应，合成了官能化苯甲醛类化合物 92. 相比之前卡宾催化酯的反应生成 $\beta$-内酯或环己二烯 产物，该反应经过对催化剂结构、溶剂和添加物的篮选， 可以 $43 \% \sim 91 \%$ 的收率得到多取代的苯甲醛产物(Eq. 12).

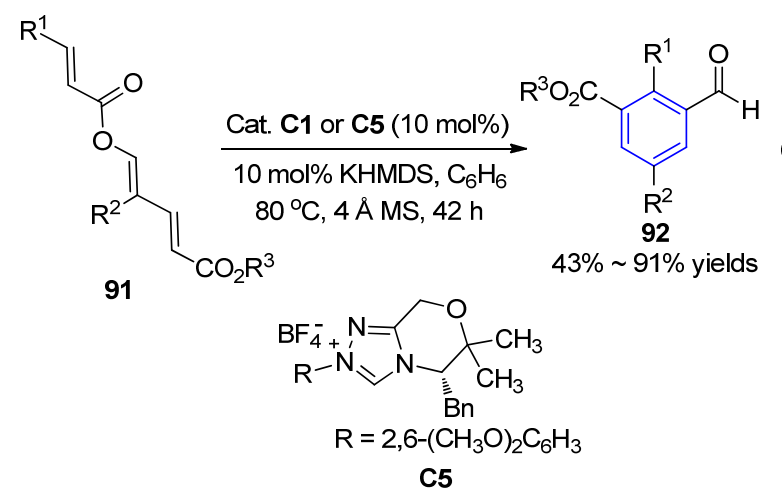

2016 年, 汪舰课题组 ${ }^{[34]}$ 利用 $\alpha$-氭基- $\beta$-甲基烯酮 93 与 $\alpha, \beta$-不饱和醛 94 为底物, 在卡宾催化下实现 $[4+2]$ 苯 环化反应，构建了一系列多取代的苯甲腈类化合物 95. 随后，叶松小组 ${ }^{[35]}$ 也报道了同样的反应，仅仅是反应条 件略有不同，反应均能以良好到优秀的收率得到苯甲腈 结构. 由于氰基的存在, 使得合成的产物可以进行多样 性转化(Eq. 13). 随后, 该小组 ${ }^{[36]}$ 将 $\alpha, \beta$-不饱和醛更换为 $\alpha$-溴代烯醛，与 $\alpha$-氰基- $\beta$-甲基烯酮 93 在卡宾催化下得 到 1,3,5-三取代苯结构化合物, 反应采用碳酸铯和 DBU 的组合，分别用于活化卡宾前体和消除氰基芳构化过 程, 高产率地得到了不对称的 1,3,5-三取代苯.

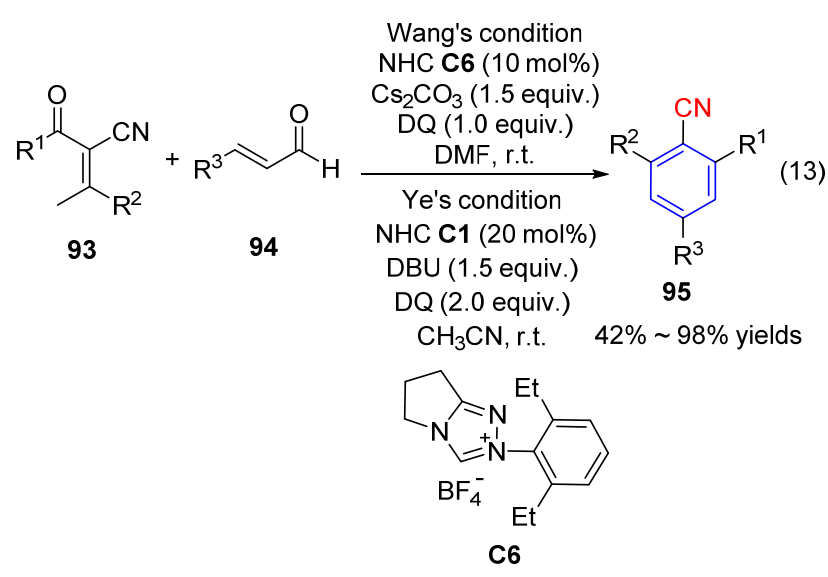

房新强等 ${ }^{[37]}$ 在研究氮杂卡宾催化 $\beta, \gamma$-不饱和 1,2-二 酮底物 96 的极性反转反应过程中, 得到多官能化的双 
环环己烯- $\beta$-内酯产物 97 或 1,2,4-三芳基取代苯环产物 98, 反应机理揭示亲核 $O$-酰基化高烯醇式中间体的生 成是反应成功进行的关键(Eq. 14). 同时, 反应产物可以 实现多种合成转化如胺化、还原或氧化等过程.

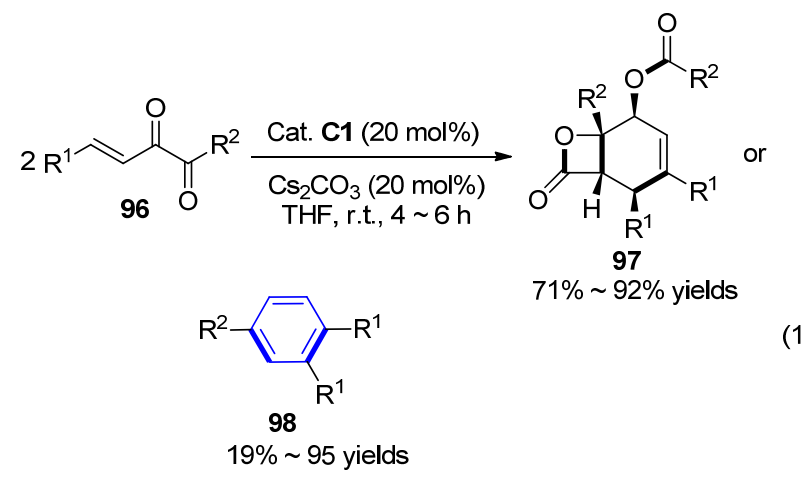

咔唑骨架广泛存在于众多活性分子和天然产物结 构中并展现出独特的生物活性. 付振乾和黄维等 ${ }^{[38]}$ 利 用卡宾催化化合物 99 与烯醛 100 的[4+2]芳环化反应成 功合成了一系列多取代咔坐类化合物 101 (Eq. 15). 该 反应具有广泛的底物适用范围、条件温和及无金属参与 等优点, 同时也可以放大到克级规模, 为探索其他芳烃 的绿色合成方法起到很好的参考作用.

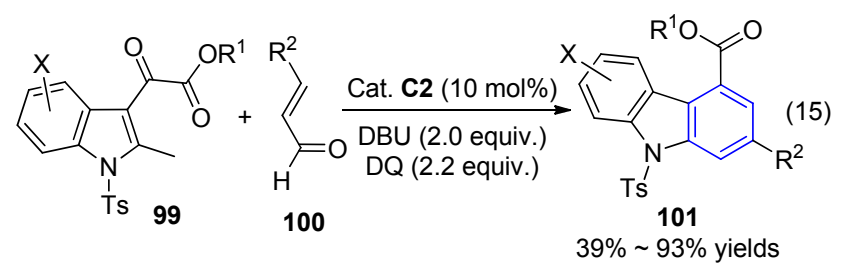

2019 年, 叶松小组 ${ }^{[39]}$ 报道了氮杂卡宾催化 $\beta$-甲基$\alpha, \beta$-不饱和醛 86 与橙酮类化合物 102 的反应, 合成了 2,2'-二羟基二苯甲酮 103 (Eq. 16). 机理研究显示卡宾催 化剂 C7 对烯醛 86 加成、氧化后, 在碱作用下得到乙烯 基烯醇式中间体，再对橙酮发生加成反应及分子内的 C-酰基化生成螺环产物, 该螺环产物在碱性条件下发生 $\mathrm{C}-\mathrm{O}$ 键断裂并经逆 Michael 加成, 最终芳构化得到 2,2'二羟基二苯甲酮类产物.<smiles>[R]C=C1Oc2ccccc2C1=O</smiles>

102<smiles>[R]/C(C)=C/C(=O)I</smiles>

86

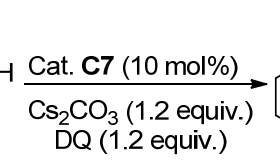
$\mathrm{Et}_{2} \mathrm{O}$, r.t.<smiles></smiles>

C7
最近, 朱庭顺课题组 ${ }^{[40]}$ 通过氮杂卡宾催化共轭二 烯醛 105 与 $\alpha$-芳基酮 104 的[4+2]苯环化实现了位阻选
择性反应，一步构建 1,2,3,5-四取代苯环，同时在 2-位形 成轴手性(Eq. 17). 该反应的底物适应性较好，底物 $\alpha$-芳 基酮 104 中有卤素、杂环、氧基、三氟甲基、磷氧化合 物等都能在体系中兼容, 给出较好的产率及 $90 \%$ 以上的 $e e$ 值. 而反应产物 106 通过简单的转化, 可以高效合成 轴手性的各类催化剂与配体. 同时, 该反应的还能与电 化学反应体系兼容, 通过氧化剂的电极循环, 可以将原 来 $2.5 \sim 3.5$ equiv. 的氧化剂减少至催化量. 该工作拓展 了氮杂卡宾作为有机小分子催化剂在催化合成方面的 应用，为轴手性化合物的合成提供了一种具有潜力的合 成手段.

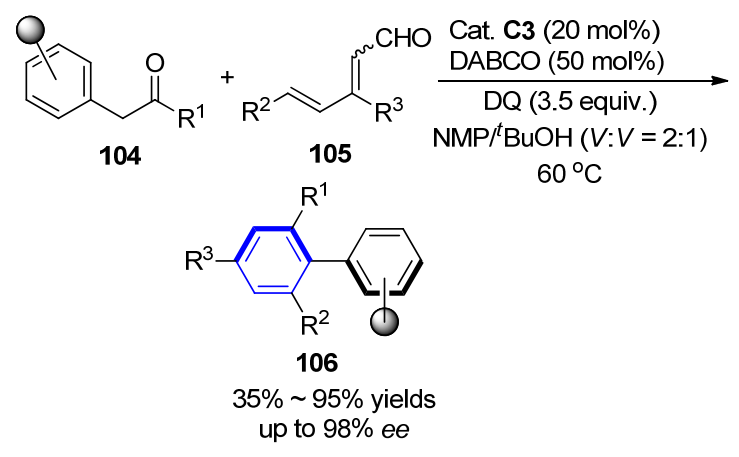

\section{4 磷酸催化苯环化的反应}

手性磷酸是一类高效、高对映选择性的 Brønsted 酸 类有机催化剂, 已被成功应用于众多不对称催化反应 中. 磷酸分子结构中磷原子上所连的羟基可作为 Brønsted 酸的酸性位点提供质子, 或与底物形成氢键作 用对亲电试剂进行活化, 而磷原子上的双键氧又可以作 为 Lewis 碱性位点提供孤对电子来活化亲核试剂, 因此 磷酸类化合物具有双功能催化剂的特点, 既能提高反应 的催化活性，又能有效地控制反应的立体选择性，从而 完成高对映选择性合成. 近年来，手性磷酸作为催化剂 被用于构建联芳基轴手性的研究成为一大热点. 其中轴 手性联荎二酚类化合物作为配体或独立催化剂使用已 被广泛关注, 其核心骨架结构也存在于众多具有生物活 性的天然产物中 ${ }^{[41]}$. 但该类化合物的合成方法却鲜有 报道，目前仅有的对映选择性合成方法主要是金属催化 的不对称氧化偶联与动力学拆分. 因此, 发展高效构建 轴手性联芳基二醇类化合物的方法仍然是有必要的.

2015 年, 谭斌小组 ${ }^{[42]}$ 报道了有机催化 2-菜酚 108 的 芳基化反应，成功实现了轴手性联萗二醇 109 的制备. 化合物 2-菜酚 108 与苯醌 107 作为起始反应底物在磷酸 类催化剂 D1 作用下能有效完成轴手性联萗二醇的合成 (Scheme 10). 通过条件优化, 该过程很好地解决了以下 关键问题: (1)选择合适的催化剂来有效控制 2-菜酚底物 中碳/氧的化学选择性; (2)催化剂能对共轭加成过程进 
行有效的立体控制; (3)在温和的条件下实现由中心手性 到轴手性的转移控制. 底物扩展显示 2-䒺酚及苯醌 107 中 2-位酯基或卤原子取代基的存在对反应的进行起到 重要作用. 值得注意的是, 合成的轴手性联荎二醇产物 109 可以作为非常高效的配体用于二乙基锌对醛的加成 反应中, 并取得高达 $98 \%$ 的 $e e$ 值, 充分显示了该方法的 适用性及轴手性联菜二醇产物的重要性. 在此研究基础 之上, 该小组继续探索有机催化在构建轴手性领域的应 用研究. 2017 年, 该小组 ${ }^{[43]}$ 首次实现了 2-菜胺 111 作为 亲核试剂对亚胺苯醌底物 110 的加成, 在相同手性磷酸 D1 催化下得到轴手性的联芳基氨基醇类产物 112 (Scheme 10). 反应机理显示手性磷酸作为双官能化催 化剂, 同时对底物苯醌 110 和 2-䒺酚或 2-䒺胺活化并促 进对映选择性共轭加成反应的发生, 进而由中心手性到 轴手性的转移和芳构化得到轴手性联芳基产物.<smiles>[R]C1=CC(=O)C=CC1=O</smiles>

107<smiles>[R]c1ccc2ccc(O)cc2c1</smiles>

08

$$
\text { (n) }
$$

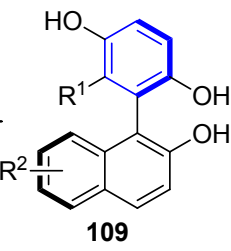

$60 \% \sim 90 \%$ yields up to $99 \%$ ee

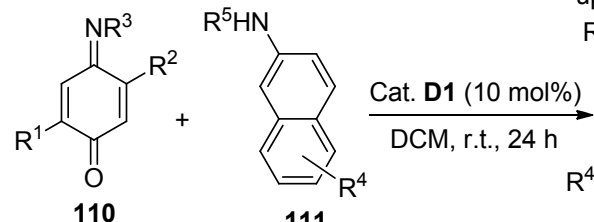
111<smiles></smiles>

$\mathrm{Ar}=2,4,6-(i-\operatorname{Pr})_{3} \mathrm{C}_{6} \mathrm{H}_{2}$

D1
图式 10 手性磷酸催化轴手性联芳基化合物的合成 Scheme 10 Synthesis of axially chiral biaryls by chiral phosphoric acid

另外, Kürti 小组 ${ }^{[44]}$ 同样报道了类似的工作, 选取苯 醌单缩醛底物 114 与 2-䒺酚 108 为底物, 在 Brønsted 酸 催化作用下得到官能化的非 $C_{2}$ 对称的联芳基结构产物 115 (Scheme 11). 该反应以 $20 \mathrm{~mol} \%$ 的三氟乙酸(TFA)或 二苯基磷酸 D2 为催化剂即可实现目的产物的高效合成, 并指出反应经由乙缩醛交换、 $[3,3]-\sigma$ 重排和芳构化路径 完成. 遗憾的是通过手性磷酸催化剂的引入也没能实现 该产物的对映选择性过程. 但随后不久, 该小组就实现 突破，报道了与 Tan 小组类似的工作，即完成了手性磷 酸 D1 催化 2-菜酚 113 与不同取代的亚胺苯醌 116 的反
应，实现了构建非 $C_{2}$ 对称的联菜二酚 117 的轴手性过 程. 通过底物结构控制实验，作者指出该反应可能经过 一步缩醛胺生成的步骤，再经[3,3]重排、苯环化得到联 芳基产物(Scheme 11) ${ }^{[45]}$.

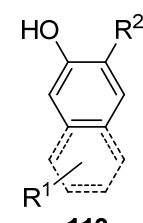

113<smiles></smiles>

(1) TFA (20 mol\%) toulene, $100^{\circ} \mathrm{C}$ (2) $\mathrm{D} 2(20 \mathrm{~mol} \%)$ $\mathrm{CF}_{3} \mathrm{CH}_{2} \mathrm{OH}$, r.t. 114<smiles>O=P(O)(O)Oc1ccccc1</smiles>
D2<smiles>[Y]N=C1C([R3])=CC(=O)C([R])=C1[R5]</smiles>

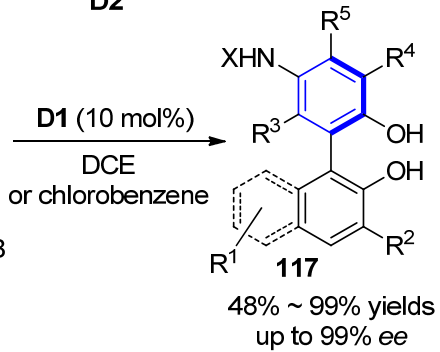

图式 11 有机催化 2-萘酚与苯醌单缩醛或亚胺苯醌构建轴手 性的反应

Scheme 11 Organocatalytic atroposelective arylation of 2-naphthol with quinone monoacetals or iminoquinones

2018 年, Maji 课题组 ${ }^{[46]}$ 报道了 Brønsted 酸催化 2烯基吲哚 118 与 1,3-二羰基化合物 119 的一锅法苯环化 反应，合成咔唑 120 或吲哚咔唑类产物(Eq. 18). 该反应 由 $25 \mathrm{~mol} \%$ 的磷酸催化剂 D2 催化, 经 $6 \pi$-电环化、空气 氧化过程得到目标产物，同时反应产物经过简单几步反 应即可实现重要药物分子的高效合成. 该方法具备了无 金属参与、底物普适性广和可规模化制备等特点，并通 过空气直接氧化的简单操作即可实现咔唑类化合物的 绿色合成.
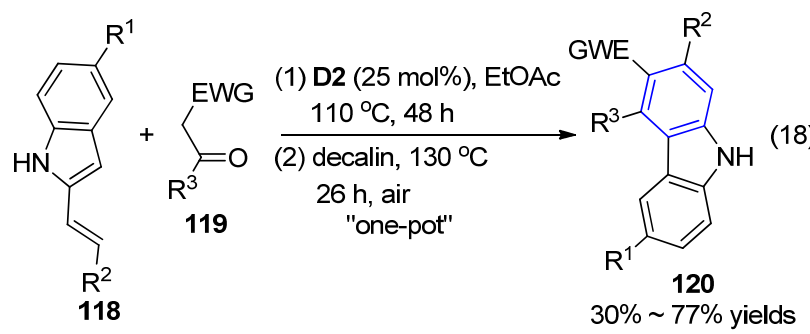

最近, 李绍玉和谭斌小组 ${ }^{[47]}$ 报道了手性磷酸催化 吲哚与苯醌的位阻异构化构建轴手性芳基吲哚骨架的 合成方法. 当采用 2-取代吲哚 122 与苯醌作为起始原料 时, 反应在磷酸催化剂 D3 催化下能很好地得到轴手性 苯基吲哚产物 123, 经过条件优化和底物扩展发现，该 
反应能以 $72 \%$ ～95\%的产率和高达 $96 \%$ 的对映选择性得 到目的产物. 而将苯醌底物替换成亚胺苯醌, 在磷酸催 化剂 D4 催化下则能很好地控制 5-差基吲哚 124 中 C-4 的亲核性，完成轴手性苯基吲哚产物 125 的合成. 值得 注意的是, 底物 5-差基吲哚 124 中 $\mathrm{N}$ 被保护后对反应的 顺利进行没有影响. 通过控制实验和机理研究发现, 底 物中吲哚的 $\mathrm{N}-\mathrm{H}$ 或 5-位羟基均可能与催化剂之间形成 氢键作用参与到反应的立体控制过程中, 进而提高反应 的对映选择性(Scheme 12).<smiles></smiles><smiles>[R]c1ccc2[nH]c([R])cc2c1</smiles>
$\underset{\text { DCM },-10{ }^{\circ} \mathrm{C}}{\stackrel{\mathrm{mol} \%)}{\longrightarrow}}$

122<smiles>[R]C1=CC([R])C([X])=CC1=O</smiles>
121

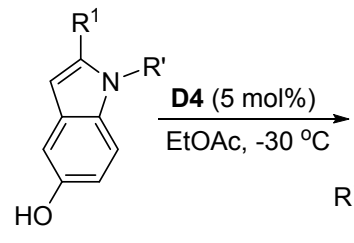
124<smiles>Cc1cc(Br)c([C@@H]2CCc3c(C)cc(Br)c(OP(=O)(O)O)c32)c2c1CCC2</smiles>

D3<smiles>[R]c1ccc2[nH]c([R])c(-c3c([R])c(O)cc([R])c3O)c2c1</smiles>
up to $96 \%$ ee<smiles>[R]Nc1cc(Cl)c(O)c(-c2c(O)ccc3c2cc([R])n3C)c1Cl</smiles>
$\mathrm{X}=\mathrm{N}, 58 \% \sim 95 \%$ yields up to $95 \%$ ee

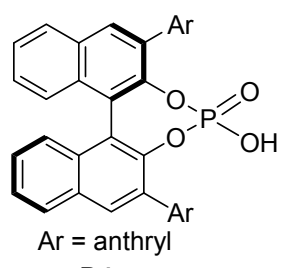

D4
图式 12 手性磷酸催化吲哚与苯醌的位阻异构化构建轴手性 芳基吲哚骨架

Scheme 12 Atroposelective construction of arylindoles by chiral phosphoric acid-catalyzed cross-coupling of indoles and quinones

\section{5 其他反应}

\section{1 酸催化芳香化反应}

2010 , 张俊良小组 ${ }^{[48]}$ 报道了三氟甲磺酸钪或三氟 甲磺酸催化化合物 127 的分子内苯环化合成多取代萗 128 和苯并芴醇类化合物 129 的方法(Eq. 19). 其中使用 $5 \mathrm{~mol} \%$ 的三氟甲磺酸, 在二氯甲烷溶剂、室温下仅 5 $\min$ 即能以高达 $98 \%$ 的收率得到多取代菜产物 128. 当 底物中取代基变为苯环时, 在三氟甲磺酸催化下以产物 苯并芴醇 129 为主; 而以三氟甲磺酸钪为催化剂时, 则 能保持以多取代萗产物为主. 因此, 在合成多取代萗和 苯并芴醇的过程中使用三氟甲磺酸和三氟甲磺酸钪能
很好地互补.

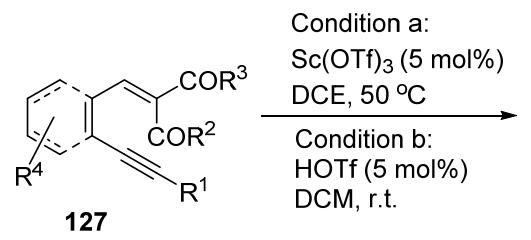

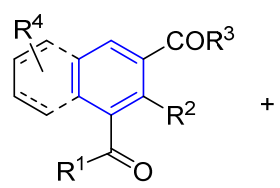

128

$15 \% \sim 96 \%$ yields

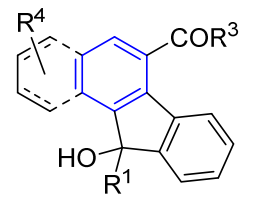

$5 \% \sim 61 \%$ yields
$129 \mathrm{R}^{2}=\mathrm{Ph}$

2014 年, 李志平小组 ${ }^{[49]}$ 报道了 $10 \% \mathrm{~mol}$ 的三氟甲 磺酸催化吲哚 130 与 $\gamma$-羰基叔丁基过氧化物 131 的苯环 化反应合成咔唑类化合物 132 (Scheme 13). 而当吲哚上 $\mathrm{N}-\mathrm{H}$ 有甲基取代时，则有两种异构产物生成. 可能原 因是有螺环亚胺正离子中间体原位生成，由于位阻导致 两类不同 1,2-烷基迁移方式形成不同产物. 值得注意的 是, 该方法能直接应用于具有重要生理活性的药物分子 Olivacine 和 Asteropusazole A 的快速合成.

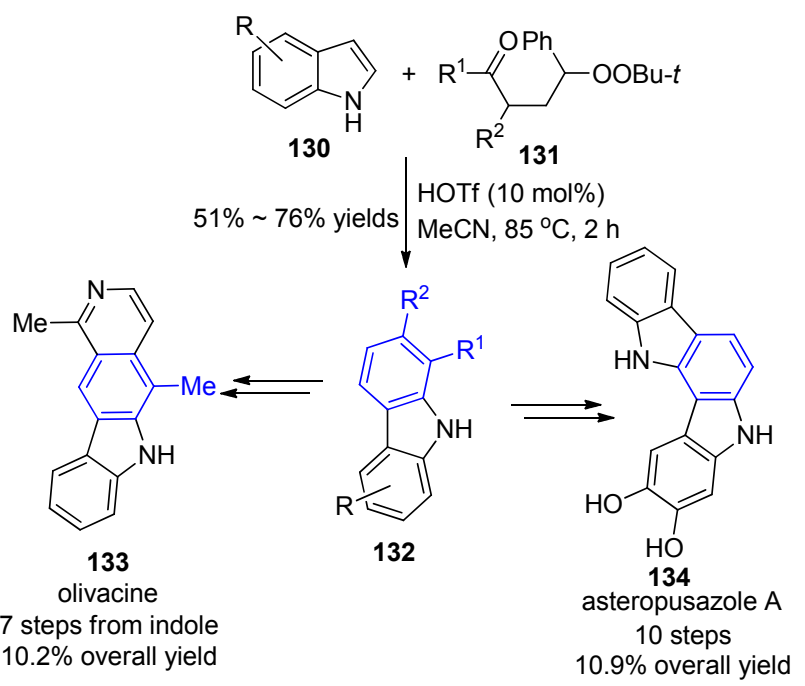

图式 13 吲哚苯环化合成咔唑及其在咔唑生物碱的合成应用 Scheme 13 Benzannulation of indoles to carbazoles and Its applications for syntheses of carbazole alkaloids

2016 年, 蔡春小组 ${ }^{[50]}$ 利用抗坏血酸 E1 作为催化剂 成功实现了邻氨基联苯 135 与炔烃 136 合成菲类多环芳 烃结构化合物 137 (Eq. 20). 该反应在亚硝酸叔丁酯和 催化量的抗坏血酸作用下生成重氮盐并经自由基过程 与端炔底物环化、芳构化得到目标产物. 用简单易得的 起始原料在无金属参与的温和条件下简单操作即可实 现菲类多芳烃结构的构建. 


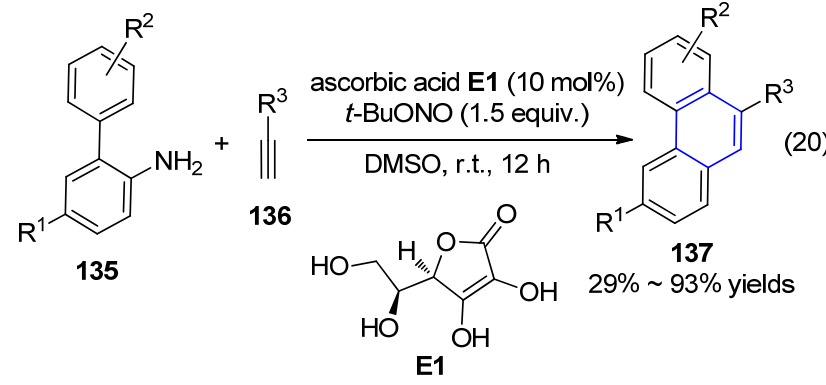

2017 年, Reddy 等 ${ }^{[51]}$ 报道了一锅法实现多环芳烃的 多步合成反应, 在 $5 \mathrm{~mol} \%$ 的对甲苯磺酸催化作用下，1,1二芳基乙醇 138 经脱水生成烯烃与丙炔醇 139 发生亲核 加成得到烯炔中间体, 接着在碱 DBU 存在下异构、电环 化并芳构化得到烯基取代的萗环产物 140 (Eq. 21). 值得 注意的是, 该方法能扩展到多芳烃结构营、䒕和苯并䒕等 化合物的高效合成，极大地拓展了该方法的实用性.

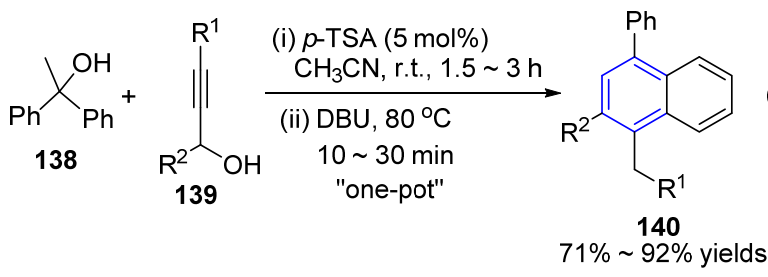

\section{2 光催化芳香化反应}

2012 年, 周磊等 ${ }^{[52]}$ 报道了曙红 $Y$ 在光作用下催化 联芳基重氮盐 141 与炔烃 142 的[4+2]苯环化反应，成 功合成了 9-或 9,10-二取代菲产物 143 (Eq. 22). 可能的 反应机理认为联芳基重氮盐在光敏剂曙红 $\mathrm{Y}$ 催化下生 成联芳基自由基，进而与炔烃发生自由基加成、环化等 串级过程. 值得注意的是该方法同样能应用于非端炔类 底物参与的反应，并以中等收率得到目的产物.<smiles>[R]c1ccc(-c2ccc([R])cc2[N+](C)(C)C(F)(F)F)cc1</smiles>

141

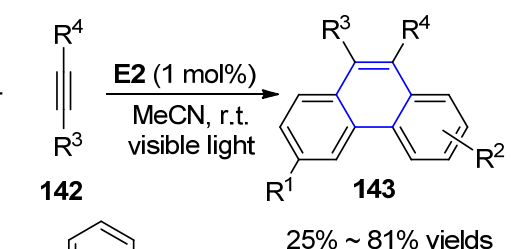

\section{6 结论}

有机小分子催化经过多年的研究积累, 取得了长足 的发展. 建立小分子催化活化模式实现多取代苯类化合
物的高效快速合成方法，成为当下有机催化领域的一个 热门课题. 通过总结发现: 第一, 有机催化合成芳香结 构化合物的新方法区别于传统合成路径, 不仅满足有机 催化的绿色、无毒、无污染及反应条件温和等优点，还 为进一步实现复杂多样的取代苯类化合物的合成提供 了路线支持. 第二，由有机催化构建苯及多取代苯类化 合物的方法可以完成取代苯类化合物的多样性合成与 转化，即通过改变底物中取代基的结构和位置，即可实 现苯环上取代基团的种类和位置变化, 为合成特定某类 取代苯类化合物提供了快速、简便的方法. 因此, 有机 催化芳香化反应的实现对反应底物的结构也存在一定 的依赖性. 第三，发展新的催化剂骨架、设计结构新颖 的候选化合物和减少催化剂的用量等问题一直是有机 催化过程面临的挑战, 同时需要考虑在构建苯环的同时 如何实现产物的手性诱导. 最后，对于新的反应模式和 机理研究还有待于进一步探索. 相信随着有机催化的发 展，更多的有机催化反应类型和结构多样的芳香结构化 合物会被合成和应用到生活的各个领域中.

\section{References}

[1] (a) McGrath, N. A.; Brichacek, M.; Njardarson, J. T. J. Chem. Educ. 2010, 87, 1348.

(b) Baumann, M.; Baxendale, I. R.; Ley, S. V.; Nikbin, N. Beilstein J. Org. Chem. 2011, 7, 442 .

[2] Davis, R.; Markham, A.; Balfour, J. A. Drugs 1996, 51, 1019.

[3] (a) O'Brien, W. M.; Bagby, G. F. Pharmacotherapy 1987, 7, 16. (b) Ricketts, A. P.; Lundy, K. M.; Seibel, S. B. Am. J. Vet. Res. 1998, 59, 1441.

(c) Thau-Zuchman, O.; Shohami, E.; Alexandrovich, A. G.; Trembovler, V.; Leker, R. R. J. Neurotraum. 2012, 29, 375.

[4] (a) Chen, Y.; Yekta, S.; Yudin, A. K. Chem. Rev. 2003, 103, 3155. (b) Brunel, J. M. Chem. Rev. 2005, 105, 857.

(c) Schenker, S.; Zamfir, A.; Freund, M.; Tsogoeva, S. B. Eur. J. Org. Chem. 2011, 2011, 2209.

[5] (a) Calloway, N. O. Chem. Rev. 1935, 17, 327.

(b) Tanaka, K. Transition-metal-mediated Aromatic Ring Construction, Wiley, Hoboken, NJ, 2013.

(c) Sunke, R.; Nallapati, S. B.; Kumar, J. S.; Kumarb, K. S.; Pal, M. Org. Biomol. Chem. 2017, 15, 4042.

[6] (a) Miyaura, N.; Suzuki, A. Chem. Rev. 1995, 95, 2457.

(b) Saito, S.; Yamamoto, Y. Chem. Rev. 2000, 100, 2901.

(c) Kotha, S.; Misra, S.; Halder, S. Tetrahedron 2008, 64, 10775.

(d) Nicolaou, K. C.; Bulger, P. G.; Sarlah, D. Angew. Chem., Int. Ed. 2005, 44, 4442 .

[7] (a) van Otterlo, W. A.; De Koning, C. B. Chem. Rev. 2009, 109, 3743.

(b) Saito, S.; Salter, M. M.; Gevorgyan, V.; Tsuboya, N.; Tando, K.; Yamamoto, Y. J. Am. Chem. Soc. 1996, 118, 3970.

(c) Gevorgyan, V.; Takeda, A.; Yamamoto, Y. J. Am. Chem. Soc. 1997, 119, 11313.

(d) Gevorgyan, V.; Sadayori, N.; Yamamoto, Y. Tetrahedron Lett. 1997, 38, 8603.

[8] Ramachary, D. B.; Ramakumar, K.; Kishor, M. Tetrahedron Lett. 2005, 46, 7037.

[9] Ramachary, D. B.; Ramakumar, K.; Narayana, V. V. J. Org. Chem. 2007, 72, 1458.

[10] Hong, B. C.; Tseng, H. C.; Chen, S. H. Tetrahedron 2007, 63, 2840.

[11] Li, S. G.; Hu, X. Q.; Jia, Z. X.; Xu, P. F. Tetrahedron 2010, 66, 
8557.

[12] Wang, H.; Li, L.; Lin, W.; Xu, P.; Huang, Z.; Shi, D. Org. Lett. 2012, 14, 4598 .

[13] Song, X.; Zhang, X.; Zhang, S.; Li, H.; Wang, W. Chem.-Eur. J. 2012, 18, 9770 .

[14] Link, A.; Sparr, C. Angew. Chem., Int. Ed. 2014, 53, 1.

[15] Fäseke, V. C.; Sparr, C. Angew. Chem., Int. Ed. 2016, 55, 7261.

[16] Magar, K. B. S.; Xia, L.; Lee, Y. R. Chem. Commun. 2015, 51, 8592.

[17] Ponra, S.; Vitale, M. R.; Michelet, V.; Ratovelomanana-Vidal, V. J. Org. Chem. 2015, 80, 3250.

[18] Jiang, L.; Li, H.; Zhou, J. F.; Yuan, M. W.; Li, H. L.; Chuan, Y. M.; Yuan, M. L. Synth. Commun. 2018, 48, 336.

[19] Liu, J. Y.; Yang, X. C.; Liu, Z.; Luo, Y. C.; Lu, H.; Gu, Y. C.; Fang, R.; Xu, P. F. Org. Lett. 2019, 21, 5219.

[20] (a) Nair, V.; Pillai, A. N.; Beneesh, P. B.; Suresh, E. Org. Lett. 2005, 7,4625 .

(b) Nair, V.; Vidya, N.; Biju, A. T.; Deepthi, A.; Abhilash, K. G.; Suresh, E. Tetrahedron 2006, 62,10136.

[21] (a) Zhou, Q. F.; Yang, F.; Guo, Q. X.; Xue, S. Synlett 2007, 2073. (b) Hu, B.; Meng, L. G.; Liu, Y. L.; Liang, M.; Xue, S. Synthesis 2009, 24, 4137.

[22] Talhi, O.; Makhloufi-Chebli, M.; Pinto, D. C.; Hamdi, M.; Silva, A. M. Synlett 2013, 24, 2559.

[23] Babu, G. N.; Ayalew, H. M.; Jain, S. Med. Chem. Res. 2014, 23, 2608.

[24] Moliterno, M.; Cari, R.; Puglisi, A.; Antenucci, A.; Sperandio, C.; Moretti, E.; Di Sabato, A.; Salvio, R.; Bella, M. Angew. Chem., Int. Ed. 2016, 55, 6525 .

[25] Hu, Z.; Dong, J.; Men, Y.; Li, Y.; Xu, X. Chem. Commun. 2017, 53, 1739.

[26] (a) Enders, D.; Balensiefer, T. Acc. Chem. Res. 2004, 37, 534.

(b) Marion, N.; Diez-Gonzalez, S.; Nolan, S. P. Angew. Chem., Int. Ed. 2007, 46, 2988.

(c) Nair, V.; Vellalath, S.; Babu, B. P. Chem. Soc. Rev. 2008, 37, 2691.

(d) Bugaut, X.; Glorius, F. Chem. Soc. Rev. 2012, 41, 3511.

(e) Hopkinson, M. N.; Richter, C.; Schedler, M.; Glorius, F. Nature 2014, 510, 485 .

(f) Flanigan, D. M.; Romanov-Michailidis, F.; White, N. A.; Rovis, T. Chem. Rev. 2015, 115, 9307.

(g) Zhang, C.; Hooper, J. F.; Lupton, D. W. ACS Catal. 2017, 7, 2583.

(h) Zhao, M.; Zhang, Y.-T.; Chen, J.; Zhou, L. Asian J. Org. Chem. 2018, 7,54.

[27] Zhu, T. S.; Zheng, P. C.; Mou, C. L.; Yang, S.; Song, B. A.; Chi, Y. R. Nat. Commun. 2014, 5, 6.
[28] Zhu, T. S.; Mou, C. L.; Li, B. S.; Smetankova, M.; Song, B. A.; Chi, Y. R. J. Am. Chem. Soc. 2015, 137, 5658.

[29] Huang, X.; Zhu, T.; Huang, Z.; Zhang, Y.; Jin, Z.; Zanoni, G.; Chi, Y. R. Org. Lett. 2017, 19, 6188.

[30] Wu, J.; Mou, C.; Chi, Y. R. Chin. J. Chem. 2018, 36, 333.

[31] Zhu, T.; Liu, Y.; Smetankova, M.; Zhuo, S.; Mou, C.; Chai, H.; Jin, Z.; Chi, Y. R. Angew. Chem., Int. Ed. 2019, 58, 15778.

[32] Hu, J. M.; Zhang, J. Q.; Sun, B. B.; Chen, J. B.; Yu, J. Q.; Yang, X. P.; Lv, H. P.; Wang, Z.; Wang, X. W. Org. Lett. 2019, 21, 8582.

[33] Candish, L.; Levensa, A.; Lupton, D. W. Chem. Sci. 2015, 6, 2366.

[34] Jia, Q.; Wang, J. Org. Lett. 2016, 18, 2212.

[35] Zhang, C. L.; Gao, Z. H.; Liang, Z. Q.; Ye, S. Adv. Synth. Catal. 2016, 358, 2862.

[36] Zhang, C. L.; Ye, S. Org. Lett. 2016, 18, 6408.

[37] Liu, J.; Das, D. K.; Zhang, G.; Yang, S.; Zhang, H.; Fang, X. Org. Lett. 2018, 20, 64 .

[38] Liu, D.; Gao, Y.; Huang, J.; Fu, Z.; Huang, W. J. Org. Chem. 2018, 83, 14210.

[39] Chen, K. Q.; Luo, Z.; Gao, Z. H.; Ye, S. Chem.-Eur. J. 2019, 25, 3253.

[40] Xu, K.; Li, W.; Zhu, S.; Zhu, T. Angew. Chem., Int. Ed. 2019, 58, 17625.

[41] (a) Chen, Y.; Yekta, S.; Yudin, A. K. Chem. Rev. 2003, 103, 3155.

(b) Brunel, J. M. Chem. Rev. 2005, 105, 857.

(c) Renzi, P. Org. Biomol. Chem. 2017, 15, 4506.

(d) Witzig, R. M.; Lotter, D.; Fäseke, V. C.; Sparr, C. Chem.-Eur. J. 2017, 23,12960.

(e) Link, A.; Sparr, C. Chem. Soc. Rev. 2018, 47, 3804.

[42] Chen, Y. H.; Cheng, D. J.; Zhang, J.; Wang, Y.; Liu, X. Y.; Tan, B. J. Am. Chem. Soc. 2015, 137, 15062.

[43] Chen, Y. H.; Qi, L. W.; Fang, F.; Tan, B. Angew. Chem., Int. Ed. 2017, 56, 16308 .

[44] Gao, H.; Xu, Q. L.; Keene, C.; Yousufuddin, M.; Ess, D. H.; Kürti, L. Angew. Chem., Int. Ed. 2016, 55, 566.

[45] Wang, J. Z.; Zhou, J.; Xu, C.; Sun, H.; Kürti, L.; Xu, Q. L. J. Am. Chem. Soc. 2016, 138, 5202.

[46] Saha, S.; Banerjee, A.; Maji, M. S. Org. Lett. 2018, 20, 6920.

[47] Lu, D. L.; Chen, Y. H.; Xiang, S. H.; Yu, P.; Tan, B.; Li, S. Org. Lett. 2019, 21, 6000.

[48] Liu, L.; Wei, L.; Zhang, J. Adv. Synth. Catal. 2010, 352, 1920.

[49] Zheng, X.; Lv, L.; Lu, S.; Wang, W.; Li, Z. Org. Lett. 2014, 16, 5156.

[50] Bu, M. J.; Lu, G. P.; Cai, C. Org. Chem. Front. 2016, 3, 630.

[51] Reddy, C. R.; Dilipkumar, U.; Shravya, R. Chem. Commun. 2017, 53, 1904.

[52] Xiao, T.; Dong, X.; Tang, Y.; Zhou, L. Adv. Synth. Catal. 2012, 354, 3195.

(Zhao, C.) 